\title{
A Qualitative Analysis of Difficulties on Transition Days in Blended Families
}

\author{
Charity Perry-Fraser, Rick Fraser \\ Department of Sociology, California State University, Los Angeles, USA \\ Email: cperry5@calstatela.edu,rfraser@calstatela.edu
}

How to cite this paper: Perry-Fraser, C., \& Fraser, R. (2017). A Qualitative Analysis of Difficulties on Transition Days in Blended Families. Advances in Applied Sociology, 7, 245-259.

https://doi.org/10.4236/aasoci.2017.76015

Received: April 17, 2017

Accepted: June 17, 2017

Published: June 20, 2017

Copyright $\odot 2017$ by authors and Scientific Research Publishing Inc. This work is licensed under the Creative Commons Attribution International License (CC BY 4.0).

http://creativecommons.org/licenses/by/4.0/

\section{(c) (i) Open Access}

\begin{abstract}
The current qualitative research study focused on the difficulties experienced by individuals in stepfamilies or blended families on transition days. A transition day is the day a child prepares to leave one custodial home and go to another, or vice-versa. Parents in various stages of stepfamily development and varying demographics were interviewed regarding transition day. The theme "difficulties" emerged throughout the coding process. Difficulties were further broken down into subthemes: difficulty and disconnect, difficulty and age of children, and difficulty and different households. Through a more indepth understanding of transition days in stepfamilies, immediate assistance may be provided to families who are in various stages of stepfamily/blended family formation. Lastly, advice for current stepfamilies and future stepfamilies is discussed.
\end{abstract}

\section{Keywords}

Qualitative, Stepfamily, Blended Family, Transition, Difficulties, Transition Daze, Transition Day

\section{Introduction}

The purpose of the current study was to gain greater understanding of transitional days in the development of stepfamilies by systematically evaluating the content of semi-structured interviews collected from family members. Transition days occur when families are in the process of forming or altering a stepfamily or blended family, and for many blended families, this is a weekly occurrence. A transition day is specifically the day a child prepares to leave one custodial home and go to another or vice-versa.

Cartwright (2012) examined the challenges of being a mother in a stepfamily and found that when transitions were managed carefully, stepparents and stepchildren felt ready to transition, leading to praise of the mother. Although, 
Cartwright's work focused specifically on the transition of remarriage, this concept can be applied to transitional days. Their results suggest that it is crucial to be patient with children who are shuffling between two households on a regular basis. Today researchers and clinicians have acquired a greater understanding of the family dynamics that lead separation and divorce. Still, the issue of transitioning between family units has been largely ignored. Addressing a family's psychological needs and their responses within the family unit during these times is incredibly important in order to foster growth and trust in a family. The current study seeks to enhance the understanding of transitional day issues for researchers and for clinicians who focus on marriage and family issues.

Stepfamilies are common. Nearly everyone has had experience with a stepfamily; they are either from one, know someone who is from one, or have a relative from one. For example, De Vaus and Gray (2003) examined transitions from cohabitation to marriage and divorce to marriage, but the issue of transitions within stepfamilies (i.e., household to household research) was largely ignored in that study. Perry-Fraser and Fraser (2016) identified and coined the term "transition daze" in previous research laying a foundation for the many trying demands of transitional days. Understanding transitional days in stepfamilies is beneficial to all stepfamilies or blended families. It is also important for clinicians who work with these families. Evidence from both non-clinical and clinical samples reveals that the first several years following formation of a stepfamily can often be turbulent (Bray \& Kelly, 1999). This is one reason why remarriages are at the greatest risk for divorce during the first five years (Clarke \& Wilson, 1994). Anything that can be done to reduce the conflict potentially preventing the dissolution of a family is welcomed. That is, knowledge or interventions, which assist children who may be involved in high conflict transitions between remarried partners, is of great importance. Children of blended families experience multiple changes in their environment. Moving households, adjusting to two households, addition or subtraction of siblings, and a change in school or social networks are but a few of the issues that children face. Multiple transitions in particular can have an effect on the psychological well-being children. Not all family transitions are equal. Some may be positive, others negative. Whether positive or negative, such transitions are dependent on a number of objective and subjective factors. For example, a child who transitions away from an abusive parental situation would more than likely be happy during a transition, while others may have divided loyalties choosing between two equally supportive households. These subjective factors make it difficult to conduct quantitative research on the process of transition.

The purpose of this study is to understand the development of a stepfamily during days of transition. The current study provides research results are applicable for clinicians in the field of marriage and family therapy and examines stepfamily narratives to further identify their experiences. The difficulties recorded on transition days within families were obtained by interviewing biological parents and stepparents who are a part of blended families. The current study 
conveys a greater understanding of difficulties on transitional days in blended families.

\section{Review of Literature}

Much is known about stepfamilies (Beer, 1992; Braithwaite, Olson, Golish, Soukup, \& Turman, 2001; Felker, Fromme, Arnaut, \& Stoll, 2002; Filinson, 1986). Ironically, the more that is learned about stepfamilies, the stronger the realization is of how little is actually known (Ganong \& Coleman, 2004; Martin-Uzzi \& Duval-Tsioles, 2013). Stepfamilies are more common in the United States than in other industrialized nations (Sweeney, 2010). The social sciences have a lengthy history of stepfamily research (Filinson, 1986; Glick, 1988; Papernow, 1984). One of the primary interests of stepfamily researchers has been on the demographic shifts our nation has experienced. Postmodern terms and variations on traditionally held themes add areas of interest and are attractive to researchers and scholars (Kunz, 2011). Such research indicates that despite social changes, stepfamilies may be quite different from first families or families of origin. Stepfamilies tend to have more conflict, are more likely to experience crises, and are slower to recover from crises (Schlomer, Del Giudice, \& Ellis, 2011). One reason for the difference between stepfamilies and families of origin is that stepparents and stepchildren must actively work to develop new bonds (Visher, Visher, \& Pasley, 2003). Research suggested that successful stepfamilies have realistic expectations about stepfamily dynamics and development. They have realistic expectations about the time necessary to establish roles and to determine their family's natural pattern of functioning (e.g. Hetherington \& Kelly, 2003; Visher et al., 2003). In order to gain greater insight into how these bonds are formed and the functioning patterns of stepfamilies, the current study will examine theoretical approaches to stepfamily transition.

\section{Theoretical Approaches to Stepfamily Transition Research}

Stepfamily research has been approached from many different theoretical perspectives. Systemic clinicians and researchers conceptualize approaches of the whole family system and recognize an equilibrium that comes with destabilization of the family. This has led to development of stage-based models grounded in family systems theory. The complete discussion of the literature of these theories is beyond the scope of this study and will not be fully explicated here. Major theories that are influential in social policy and among practitioners will be discussed. Discussion will be limited to theories that may be relevant for elucidating factors associated with successful and unsuccessful transitions. Conflict Theory and Stage Theory are introduced in this section to better explain stepfamily transition research in the context of the transition day.

Conflict Theory. Conflict theory is closely aligned with neo-Marxism (Sallach, 1973). From a conflict theorists perspective, the blended family attempts "fit" two family systems together. Conflict may arise during this time, and difficulties 
must be addressed for the family to maintain equilibrium.

Conflict theory assumes individuals have different interests and amounts of power, which put them at odds with each other. When applied to the family, it assumes members of a family unit will differ in preferences, interest and motivations. Conflict within a blended family can also exist in the form of differences in age, gender, authority, power and privilege. Gains for one family member can be losses for another, creating competition among family members that can lead to confrontational behavior, or behaviors that are competitive such as threats, promises or appeasement. When applied to families, conflict theory assumes that solutions that everyone can agree upon must be found before a conflict can end. Compromise among the members of the family unit must exist so that the family unit is able to function and maximally meet the goals of its members. When families find difficulty in finding common ground, conflicts must be negotiated to gain consensus and restore the family's equilibrium. In stepfamilies, the need to reestablish oneself on a weekly basis may add to difficulty on days of transition.

During days of transition, normative pressures to conform to a different set of expectations associated with each household, and the need to adjust after having spent time apart from a particular family unit may increase conflict. Stepfamily systems tend to evolve based on responses to individual and systemic changes of the entire family. To explore this in more depth, stage theory is examined.

Stage Theory. In the current study, a questionnaire was created with questions that mirror modern stage theories. For children of stepfamilies, feelings can be conflicting and complicated by social, emotional, and developmental matters (L'Abate, 1976, 1986). The researchers of the current study recognize stages are not necessarily rigid and sequential. In other words, families may fluctuate between the stages (McManus-Gay, 2002; Papernow, 1993). The current study utilizes Papernow's argument that members of the stepfamily are often in different stages from one another. The current study explicates additional ways in which a family may grow toward developing greater cohesiveness. In order to explore the ideas held by the interviewees in the current study, it is important to understand how individuals cope with adversity in various stages in a stepfamily. Individual and coping theories are examined to gain a greater understanding about how to create a space for greater family development and greater empathy toward family members during days of transition. Individuals cope differently under various pressures. Below, individual and family coping theories are explored.

\section{Individual and Family Coping Theories}

Coping in ordinary parlance is the ability to strive with some degree of success against adversity (Nuttman-Shwartz \& Dekel, 2009). Other definitions emphasize adversity and the availability of resources needed for successful resolution (Matthews \& Campbell, 2009; Riolli \& Savicki, 2010). Hans Selye (1976) developed a theory of stress that was foundationally based on the concepts of stress, distress and exhaustion. In the blended family unit, threats may be perceived 
among family members, therefore coping defenses may vary among family members in their efforts to deal with stressors. According to Pearlin and Schooler (1978) coping represents an individuals' effort to deal with stressors. Newer accounts of coping are based on alternative theories, but many also emphasize individual differences (Scholer \& Higgins, 2010; Skočić, Rudan, Brajković, \& Marćinko, 2010).

It is therefore imperative to identify what is happening within the family system to gain a greater understanding of the individual, coping mechanisms, empathy and adaptation. Transitions require empathy and patience toward the individual who is experiencing internal changes and their concomitant behavior. The current study explicates interviewees' reflections on behaviors of family members as well as their own behaviors, during transitional days. The family systems approach expands the frame of reference to include all of the forces at work within a family unit (L'Abate, 1981). Accordingly, family transitions are more likely to be difficult if those who are involved believe the transition to be unfair or overwhelming (Guerin, 1976). When families respond to stress in a positive manner they are said to adapt. Adaptation is the ability of the family and its members to make changes that are needed to recover from a stressor.

Stepfamilies and their member's ability to adapt to a stressful situation depends on the needs of individual family, and its members along with other factors such as the needs of extended family members, a family's social institutions, the larger environment. Successful resolution often requires changes in roles, rules, interactional patterns and perceptions of family members (McCubbin, Cauble, \& Patterson, 1982). Adaptation should not be perceived as an end product that is definitive, as stepfamilies continue to adapt as other stressors come into play. Family stress theory has evolved over the past few decades. Although linear theories that reflect stage processes in families have been helpful to the field of marriage and family therapy, many family theorists believe that families should be viewed nonlinearly, as discussed in the next section (Kaslow et al., 2011; Minuchin, 1974; Rigazio-DiGilio \& McDowell, 2013).

\section{Methodology}

Qualitative research methods are used to examine the content surrounding the difficulties newly constituted families face on days of transition. Qualitative methods have been shown to be useful for the types of multi-layered systems that families are rooted in whereby research questions are often open-ended and exploratory. Narrative inquiry was utilized for this study. It allowed for an indepth investigation of changing experiences in stepfamilies and similar methodologies as found in grounded theory approach.

Glaser and Strauss (1967) developed the grounded theory approach as a response to the shortcomings of traditional hypothesis-testing. Grounded theory has been shown to be appropriate to understand familial processes (Morse \& Richards, 2002), such as transitional days in stepfamilies. Grounded theory methods are well suited for examination of the links between reported experiences 
and the interpersonal processes of an individual (Clawson \& Ganong, 2002). Through the use of grounded theory, categories of meaning emerge from which thematic analysis can be applied to narratives. Grounded theory approaches have been used in qualitative interviewing because they allow for certain concepts to be explored in greater depth, which in turn allows the feedback to shape further inquiry (Burck, 2005).

The current study utilizes narrative inquiry as a method for simultaneous representation of both personal and social conditions, as was done previously by Clandinin (2006). They discussed personal conditions in the context of social conditions to describe life events. Blended families experience many events that have led them to the current union. Tactful inquiry, open to respondent's directions and feelings, allows for elicitation of their subjective experiences.

\section{Participant Selection}

\subsection{Participants}

The current study involved in-depth, semi-structured face-to-face interviews with thirteen parents of a blended or step family along with a demographic questionnaire. Names were changed in the narratives to protect confidentiality. The names of seven participants were changed in accordance with standard qualitative research guidelines (Creswell, 2009). The researcher assigned a code for each participant, ranging from P1 to P13.

\subsection{Summary of Demographics}

Thirteen participants consented to be interviewed for this study. The current study focused only on blended families or stepfamilies therefore and all of the participants were involved in a family unit that met these criteria. Participants' ages ranged from 30 years old to 69 years old, and $38 \%$ of interviewees fell in the range of 30 years old to 39 years old. Of the 13 participants, 9 were female and 4 were male. The interviewees ethnic identities were: Caucasian, African-American, Asian, and Latino/Latina; 46\% of the interviewees were Caucasian. All thirteen interviewees identified as a biological parent in a blended family unit or a step-parent to a child in the family unit. Interviewees represented some of the religious categories included in questionnaire, whereby the categories were: Buddhism, Catholic/Christian, Islam, Hindu, Jewish, Muslim, Sikh, other religion and no religion. The interviewees identified the following religions from the categories listed above Catholic/Christian, Buddhism, Christian, or no religion. Specifically, $30 \%$ of the interviewees were Catholic/Christian, 30\% Christian, $15 \%$ Buddhism, $15 \%$ no religion and $10 \%$ identified as Buddhist/Catholic/ Christian. Educational attainment was assessed whereby $38 \%$ reported having completed a graduate degree, $30 \%$ reported having completed a four-year degree, $15 \%$ reported having completed a post-graduate degree, $10 \%$ reported having completed a two-year degree, and $10 \%$ reported having completed high school. Reported occupations were: banker, talent agent, registered nurse, administrator, paralegal, tennis coach, musician, yoga teacher, student, writer, of- 
fice manager and physician.

For the current study, $70 \%$ of the interviewees were previously married and $30 \%$ were never been married. Length of previous marriages ranged from 4 years to 14 years. Not every interviewee had children from a previous relationship. The ages of the children ranged from 5 years old to 37 years old. The percentage of time a child spends with the interviewee's family was recorded. The time spent with the identified parent ranged from $20 \%-100 \%$ of the week. It is important to note that for the children who spent $100 \%$ of the time with the custodial parent there was still some contact with the non-custodial parent from time to time. The current study also elicited information about the other parent of the child and found that $40 \%$ of previous spouses had remarried, with time of remarriage ranging from 10 days to 4 years. Children were present in these homes $54 \%$ of the time and the ages of the children ranged from 6 years old to 19 years old. Interview questions also addressed whether or not the current family unit cohabitated with their current spouse/partner before marriage; $53 \%$ of the interviewees had cohabitated before blending their current family unit. Children's ages at the time of cohabitation/marriage ranged from 2 years old to 17 years old. Current family members in the household of interviewees reported having: no additional family members in the household, stepchildren in the household, biological children in the household or extended family members in the household.

\section{Data Analysis Findings}

The goal was to describe the participants' subjective experiences and views.

The first level of identification was performed during the initial review of each interview transcript. The resulting theme difficulties and its subthemes are described below.

The theme of difficulty was identified from the coding process and further classified into subthemes. The findings for the research questions are summarized with brief quotes that exemplify the themes or subthemes. Table 1 shows the frequency of difficulty as a theme appeared across interviews.

Theme: Difficulties. Interviewees referenced common difficulties of transitions between custodial and non-custodial parent's homes. Subthemes were disconnect, age of kids, and different households.

Subtheme 1: Disconnect. The primary subtheme was disconnect. Interviewees reported feeling disconnected with their stepchildren. It was mentioned 17 times

Table 1. Frequency of themes for research questions.

\begin{tabular}{ccc}
\hline Theme and Subthemes & N Mentioning & Exemplar Quotes \\
\hline Difficulties & 3 & 17 \\
Disconnect & 8 & 15 \\
Age of kids & 4 & 8 \\
Different households & 4 & \\
\hline
\end{tabular}


in three interviews. Participant 5 described the feelings she had towards her stepchildren, saying

"It was really hard. I mean there were many times that it was on the edge of disdain, which is a terrible feeling to have about the children that you love." Participant 9 expressed a preference for spending time when her stepchild is not at home, saying, "And it's kind of horrible but I prefer it. I love my stepdaughter, but I prefer it... because she brings part of her mother into the-into the equation."

Participant 7 actively sought out ways to spend as little time with her stepchildren as possible sharing:

"I would just make plans to do other things. You know go hang out with my mom, my friends, whatever, work late um, just because of how-how they behaved and I think that the attachment they were starting to get to me seemed... it just was different to me and I wasn't... I didn't really like it.”

Participant 7 added, "They're not my children, they not reflective at all of who I am."

Subtheme 2: Age of kids. The second subtheme of difficulties involved older children. Interviewees referenced difficulties associated with transitioning older children into a blended family, as well as difficulties of children going through their pre-teens and teen years. Some participants recognized that the behavioral changes during the preteen years may just be part of growing up and not necessarily a result of divorce and blended families.

This subtheme was mentioned fifteen times in eight interviews. While Participant2 described a good blended family situation, she added:

"Everything has shifted in the last year. So, it is like all of my answers have this caveat of that I have a teenager now, and so that has been a shift in that there is a lot of, I see her kind of pushing the rules."

Participant 12 shared about her stepdaughter, stating:

"Between 11 and 13, she absolutely wanted nothing to do with us. She refused to come visit us, we would come and want to pick her up for visits and she did not want anything to do with us. She, at some point told us also that, she didn't like coming to our house when the other kids were there because the attention was not on her."

Participant 4 opined, "I feel really lucky, they were one and three. I know it would be a completely different story if I got them at eight and ten." Participant 7 added, “... You know, other people's 8 and 10-year-olds, I'm not that interested."

Subtheme 3: Different households. The third subtheme of difficulties was different across households. Interviewees referenced difficulties associated with two households involving both parents and children. It was mentioned eight times in four interviews. Participant5 described having similar household rules with her ex-husband, saying: 
"As they have gotten older we don't have to check in with each other as much. However, the rules are completely different for the children at their house and our house, so I feel that is much more difficult for them."

Participant 10 shared, "And so it was this constant struggle with those things because there were two different households, two different sets of rules, two sets of what's important." Participant 7 said,

"I feel like the kids really should feel comfortable no matter where they are and it would be better if parents could agree on rules and other things and keep them consistent, but realistically it is not going to happen."

\section{Conclusion}

In summary, the researcher thoroughly read the transcripts and mined them for emergent themes. Each transcript was read numerous times before moving on to the next transcript. Through this method of data analysis, the researcher was able to bring forth each participant's voice on the themes highlighted above. The main research question was: Are different processes involved when moving from a custodial parent's home to a non-custodial parent's home and vice-versa? A primary theme was difficulties.

\subsection{Overall Findings}

Difficulties were a theme elicited from the data analysis. Disconnect, age of children and different households were subthemes of the theme, difficulties.

Difficulty and disconnect. Interviewees referenced common difficulties of transitions between custodial and non-custodial parents' homes. Further exploration of the primary theme, difficulty, elucidated subthemes of disconnection, age of children, and different households. Interviewees remarked 17 times in three individual interviews that there was a disconnection with stepchildren. One interviewee remarked that disconnections were brought in by the child merely having the biological equation of the other parent thus creating a disconnect. Another interviewee revealed there were times when feelings of disdain were present and she felt bad about that because she did love her stepchildren. There were times that interviewees actively sought out disconnection by being involved in other tasks to avoid connecting with their stepchildren.

Difficulty and age of children. The second subtheme of difficulty involved older kids. Interviewees referenced the difficulties associated with transitioning older kids into a blended family. Some interviewees recognized that the behavioral changes during the preteens may just be part of growing up and not necessarily the result of divorce and of blended families. The subtheme was mentioned fifteen times in eight interviews. An interviewee shared that she attributes some of the behaviors of her older stepchild to stereotypical teenage behavior such as pushing limits. The realization that a stepchild is an age appropriate teenager created a better blended family atmosphere for her. Other older stepchildren were described by their stepparents as wanting nothing to do with them. It 
was also discovered that older children struggled because there were other children in the house, reducing attention for that stepchild. Other interviewees remarked that they felt lucky because they had been in the picture since the children were very young. They indicated that they probably would not have been as interested in their stepchildren had they been older when the blended family was created.

Difficulty and different households. The third subtheme of difficulty was difficulties associated with living in different households. Interviewees referenced difficulties for parents and children associated with dealing with two households. It was mentioned eight times in four interviews. One of the greatest challenges interviewees faced was the existence of different rules for the different households. Some participants remarked that as their children aged they did not have to check-in with them as often. Still there were difficulties that children experienced due to the changing rules between households. One interviewee remarked that agreement of rules between the two households was not possible, and that participant acknowledged that it would be preferable if the rules were similar.

\subsection{Discussion of Findings/Conclusion}

This study was intended to explore and develop a fundamental understanding of transitional days in stepfamilies. The main research question was: Are different processes involved when moving from a custodial parent's home to a non-custodial parent's home and vice-versa? Participants described difficulties. Qualitative software (Atlas.ti) was used to further capture the voice of the interviewee.

Through interviews, valuable information for individuals who are involved in a stepfamily/blended family environment was explored. The results of the current study yielded the theme: difficulties.

The participants of the current study had diversity with respect to age, gender, marital status, ethnicity, parental status (bio-step), religion, educational attainment, occupational diversity, previous marital statuses and custody arrangements. marriage or the partnership with their current mate was also collected.

For the current study, $70 \%$ of the interviewees had been previously married and $30 \%$ had never been married. Length of previous marriages ranged from four years to 14 years. Not every interviewee had children from a previous relationship. For the interviewees who did have children from a previous marriage, the children's ages ranged from five to 37 years old.

This researchers' objective was to identify the difficulties of transition days in blended families and relate their stories to emergent themes found in the data of the thirteen interviews.

The theme difficulties call to mind the disconnection and reassembly of the family system.

Conflict theory highlights how harmony in blended and stepfamilies can exist. When applied to the family, conflict theory assumes that members of a family unit will differ in preferences, interests and motivations. In the current study, 
most families interviewed differed in these respects. Conflict within the interviewed families was also in the form of age and gender differences. Conflict theory, when applied to the family assumes solutions can be agreed upon by all family members. In the current study, easing conflict in days of transition through specific approaches, as discussed below, varied between families. Compromising by parents facilitated harmony in finding common ground to negotiate consensus in the family unit resulting in less role strain among the family members.

Among the primary challenges identified by the 13 families in the current study, was the children's sibling role change. Age of the child in this sense became secondary to the child's position in family when new families were reconstituted. There is little or no research regarding the effects of long term role change in literature today. However, we can speculate that because kids of divorce seem to have an easier time in adjusting to new situations after they leave the household (i.e., College, military), it can be presume that these children benefited from having to take on different roles in different households. This is the most positive aspect of the change in households. On the other hand, it is equally reasonable to assume that children who may have experienced a favored role (i.e., the eldest child in a household) when placed in a new household, may experience loss of status, power, and authority. While this research did not address this directly, it is presumed that parental intervention would be the primary mediating factor during this kind of role change. Attitudes of parents toward the children and recognition of their previous role and new role is crucial in being able to assuage the emotional experience of a child who has lost their status.

Conflict theory argues that there is no reason for a family member to oppose harmony (Sprey, 1969). The current study explored this issue and determined that most families tried to create space for the children in the family by debriefing those children during days of transition. The researcher of the current study discussed stage theory. The current study supports the notion that different stages may be present, static and not necessarily rigid or sequential for families during transitional days. Stepfamily or blended family members are typically in different stages and must find various ways to grow toward cohesiveness. In the current study, interviewees described creating such cohesiveness by establishing family routines such as eating dinner together on specific nights in order to create greater cohesion among the members of the family unit.

A final aspect under the theme of difficulties, which is similar to the change in roles theme, is the change in rules by which family systems operate. These rules exhibit both conscious and unconscious attitudes that manifest in a variety of behaviors. Conscious decisions such as bedtimes, chore duties, and discipline, are among the clearest examples of rule setting. These conscious rules must be navigated by children during transitional days. Unconscious rules such as attitudes toward education, feelings about the other parent, ways in which to get the parent's attention, and respect, are not clearly formatted within families and are oftentimes overlooked when parents talk about difficulties. While one child may 
be acting out because one parent is assigning the homework to be completed in a certain way, the underlying concern may be a power battle between the parent and the child (whether step or biological parent), which that child does not encounter in the other household. In this scenario, parents may misidentify a child's behavior as not wanting to follow through with rules or as being rebellious, when in fact child may be attempting to engage support from parents in a way that works in the other family unit. From the child's perspective, what works for one parent may not work for another.

In summary, the primary difficulties observed during transition days involved disconnection and reassembly of a family system; an adjustment by the child to a new role and therefore, a new family position or status; and adjustment of parents and the child to as structure that is congruent with a stable family system. All of these aspects create and necessitate a change in the status quo. Change can be stressful and chaotic and thus parents have the obligation to mediate how this change is experienced. This is achieved primarily through the attitudes and behaviors of the parents. The next section will examine how parents manage the transitions, which was the second most common theme in the current study.

Individual and coping theories were also discussed. Those theories are applicable to interviewees' reflections of behaviors during transitional days. McCubbin, Cauble, \& Patterson (1982) argued that a stepfamily's ability to adapt to the needs of individual family members often requires changes in roles, rules, interactional patterns and perceptions.

\section{Limitations of the Current Study}

As in all research studies, there were unavoidable limitations. The first limitation is that different interpretations of the material were possible. This subjectivity could have led to the second limitation, which is generalizability of results. The current study sought out 13 individuals who were in various stages of transition in family unit structure. Arguably the subjective nature of the current study minimizes generalizability to a larger population. Third, my personal biases may have influenced the participant's responses. The fourth limitation is the shifting demographics and backgrounds of the interviewee's. Questions for the current study varied in interpretation for the interviewees, who varied in cultural backgrounds, age, education attainment and race.

With the aforementioned limitations acknowledged, the narratives were analyzed to elucidate themes from the narratives as expressed by the interviewees. Notably, there were strengths and weaknesses of the narrative approach used in this study.

\subsection{Strengths and Weaknesses of Narrative Inquiry Interviewing}

Strengths of narrative inquiry include possible benefits to the research participants in the form of a greater understanding of the power dynamics (whether social, cultural, political or historical) that can play out during family transitions. Application of meaning elucidated in the current research study revealed the 
quality of relationship dynamics that typical research methods cannot deliver. Experientially, strengths of narrative inquiry toward cultural contexts constructed an even greater cross-section among disciplines, marriage and family therapy, epistemologies and other theoretical commitments.

Weaknesses of narrative inquiry involved unreasonable expectations during the interview. An example of unreasonable expectations is when a participant makes assumptions about the knowledge the researcher has on the topic. Also, interviewees may realize that he or she is not the first to be interviewed, and this may lead them alter their narratives (Jovchelovitch \& Bauer, 2000).

Interpretation of data through narrative inquiry and theme analysis is based on the assumption that the interviewee has given a truthful account of events. However this may not be the case as interviewees may have had a hidden agendas, rendering non-authentic information to the interviewer.

\subsection{Advice for Current Future Stepfamily/Blended Family Members}

Difficulties during days of transition are largely related to feelings. The feelings of children are often overwhelming and they are unable to communicate their feelings to their loved ones. Being thoughtful in one's approach to children during days of transition takes work. Allowing a child the emotional room and physical time to adjust to their current surroundings allows for stronger connections among the family. Difficulties abound in stepfamily family relationships because they began with a loss. That is, through the loss of the ideal family, families are required to navigate unchartered waters, which require exploration of thoughts and feelings, and more importantly dealing with the grief and loss that comes from the changes associated with a separation.

Transition day for parents, requires the self-acknowledgement of the parent that "normal" on days of transition may fluctuate and this requires flexibility and patience on the part of the parent. Emotions run strong on days of transition. Children may be anxious, withdrawn, push boundaries, or react with far greater intensity on the first day of re-entry or day of exit than family members experience during the other days of visitation. It is incredibly important to be patient with one's child or step-child on this day. Oftentimes, as children get older, transitions become more routine. Giving a child room to re-center themselves in their "new" surroundings is essential for smooth transition days.

\section{References}

Beer, W. R. (1992). American Stepfamilies. Piscataway, NJ: Transaction Books.

Braithwaite, D., Olson, L., Golish, T., Soukup, C., \& Turman, P. (2001). "Becoming a Family": Developmental Processes Represented in Blended Family Discourse. Journal of Applied Communication Research, 29, 221-247.

https://doi.org/10.1080/00909880128112

Bray, J. H., \& Kelly, J. (1999). Stepfamilies. Random House Digital, Inc.

Burck, C. (2005). Comparing Qualitative Research Methodologies for Systemic Research:

The Use of Grounded Theory, Discourse Analysis and Narrative Analysis. Journal of 
Family Therapy, 27, 237-262. https://doi.org/10.1111/j.1467-6427.2005.00314.x

Cartwright, C. (2012). The Challenges of Being a Mother in a Stepfamily. Journal of Divorce \& Remarriage, 53, 503-513. https://doi.org/10.1080/10502556.2012.682904

Clandinin, D. J. (2006). Narrative Inquiry: A Methodology for Studying Lived Experience. Research Studies in Music Education, 27, 44-54. https://doi.org/10.1177/1321103X060270010301

Clarke, S. C., \& Wilson, B. F. (1994). The Relative Stability of Remarriages: A Cohort Approach Using Vital Statistics. Family Relations, 43, 305-310. https://doi.org/10.2307/585422

Clawson, J., \& Ganong, L. (2002). Adult Stepchildren's Obligations to Older Stepparents. Journal of Family Nursing, 8, 50-72. https://doi.org/10.1177/107484070200800104

Creswell, W. (2009). Research Design: Qualitative, Quantitative, and Mixed Methods Approaches. Thousand Oaks, CA: Sage.

De Vaus, D., \& Gray, M. (2003). Family Transitions among Australia's Children. Family Matters, 65, 10-17.

Felker, J. A., Fromme, D. K., Arnaut, G. L., \& Stoll, B. M. (2002). A Qualitative Analysis of Stepfamilies: The Stepparent. Journal of Divorce \& Remarriage, 38, 125-142. https://doi.org/10.1300/J087v38n01_07

Filinson, R. (1986). Relationship in Stepfamilies: An Examination of Alliances. Journal of Comparative Family Studies, 17, 43-61.

Ganong, L. H., \& Coleman, M. (Eds.). (2004). Stepfamily Relationships: Development, Dynamics, and Interventions. New York, NY: Kluwer Academic/Plenum Publishers. https://doi.org/10.1007/978-1-4419-9112-6

Glaser, B. J., \& Strauss, A. (1967). The Discovery of Grounded Theory: Strategies for Qualitative Research. Chicago: Aldine Publishing.

Glick, P. C. (1988). Fifty Years of Family Demography: A Record of Social Change. Journal of Marriage and the Family, 50, 861-873. https://doi.org/10.2307/352100

Guerin, P. J. (1976). Family Therapy: Theory and Practice. New York, NY: Gardner Press, Distributed by Halsted Press, c1976.

Hetherington, E. M., \& Kelly, J. (2003). For Better or for Worse: Divorce Reconsidered. New York, NY: W. W. Norton \& Company. https://doi.org/10.1037/12353-030

Jovchelovitch, S., \& Bauer, M. W. (2000) Narrative Interviewing. In: Bauer, M. W., \& Gaskell, G. (Eds.), Qualitative Researching with Text, Image and Sound: A Practical Handbook (pp. 57-74). London: SAGE.

Kaslow, N. J., Bhaju, J., \&Celano, M. P. (2011). Family Therapies. In S. B. Messer, \& A. S. Gurman (Eds.), Essential Psychotherapies: Theory and Practice (3rd ed., pp. 1-48). New York, NY: Guilford Press.

Kunz, J. (2011). Think Marriages and Families. Boston: Pearson.

L'Abate, L. (1976). Understanding and Helping the Individual in the Family. New York, NY: Grune \& Stratton.

L'Abate, L. (1981). Classification of Counseling and Therapy Theorists, Methods, Processes, and Goals: The E-R-A Model. The Personnel and Guidance Journal, 59, $263-$ 265. https://doi.org/10.1002/j.2164-4918.1981.tb00546.x

L’Abate, L. (1986). Systematic Family Therapy. New York, NY: Brunner/Mazel.

Martin-Uzzi, M., \& Duval-Tsioles, D. (2013). The Experience of Remarried Couples in Blended Families. Journal of Divorce \& Remarriage, 54, 43-57.

https://doi.org/10.1080/10502556.2012.743828 
Matthews, G., \& Campbell, S. E. (2009). Sustained Performance under Overload: Personality and Individual Differences in Stress and Coping. Theoretical Issues in Ergonomics Science, 10, 417-442. https://doi.org/10.1080/14639220903106395

McCubbin, H. I., Cauble, A. E., \& Patterson, J. M. (1982). Family Stress, Coping, and Social Support. Springfield, IL: Charles C. Thomas.

McManus-Gay, A. (2002). From Discord to Harmony: Creating a Stepfamily Paradigm. Proquest Information and Learning. UMI.

Minuchin, S. (1974). Families and Family Therapy. Cambridge, MA: Harvard University Press.

Morse, J. M., and Richards, L. (2002). Readme First for a User's Guide to Qualitative Methods. Thousand Oaks, CA: Sage Publications.

Nuttman-Shwartz, O., \& Dekel, R. (2009). Ways of Coping and Sense of Belonging in the Face of a Continuous Threat. Journal of Traumatic Stress, 22, 667-670. https://doi.org/10.1002/jts.20463

Papernow, P. L. (1984). The Stepfamily Cycle: An Experiential Model of Stepfamily Development. Family Relations, 33, 355-363. https://doi.org/10.2307/584706

Papernow, P. L. (1993). Becoming a Stepfamily: Patterns of Development in Remarried Families. San Francisco, CA: Jossey-Bass.

Pearlin, L., \& Schooler, C. (1978). The Structure of Coping. Journal of Health and Social Behavior, 19, 2-21. https://doi.org/10.2307/2136319

Perry-Fraser, C. P., \& Fraser, R. (2016). Transition Daze: A Qualitative Analysis of Transition Days in Blended Families. Psychology, 7, 1110-1118.

Rigazio-DiGilio, S. A., \& McDowell, T. (2013). Family Therapy. In J. Frew, \& M. D. Spiegler (Eds.), Contemporary Psychotherapies for a Diverse World (pp. 415-458). New York, NY: Routledge/Taylor \& Francis Group.

Riolli, L., \& Savicki, V. (2010). Coping Effectiveness and Coping Diversity under Traumatic Stress. International Journal of Stress Management, 17, 97.

https://doi.org/10.1037/a0018041

Sallach, D. L. (1973). Critical Theory and Critical Sociology: The Second Synthesis. Sociological Inquiry, 43, 131-140. https://doi.org/10.1111/j.1475-682X.1973.tb00710.x

Schlomer, G. L., Del Giudice, M., \& Ellis, B. J. (2011). Parent-Offspring Conflict Theory: An Evolutionary Framework for Understanding Conflict within Human Families. Psychological Review, 118, 496. https://doi.org/10.1037/a0024043

Scholer, A. A., \& Higgins, E. T. (2010). Regulatory Focus in a Demanding World. In Handbook of Personality and Self-Regulation (pp. 291-314). https://doi.org/10.1002/9781444318111.ch13

Selye, H. (1976). The Stress of Life (Revised ed.). New York, NY: McGraw Hill.

Skočić, M., Rudan, V., Brajković, L., \& Marčinko, D. (2010). Relationship among Psychopathological Dimensions, Coping Mechanisms, and Glycemic Control in a Croatian Sample of Adolescents with Diabetes Mellitus Type 1. European Child \& Adolescent Psychiatry, 19, 525-533. https://doi.org/10.1007/s00787-009-0066-z

Sprey, J. (1969). The Family as a System in Conflict. Journal of Marriage and Family, 31, 699-706. https://doi.org/10.2307/349311

Sweeney, M. M. (2010). Remarriage and Stepfamilies: Strategic Sites for Family Scholarship in the 21st Century. Journal of Marriage and Family, 72, 667-684. https://doi.org/10.1111/j.1741-3737.2010.00724.x

Visher, E. B., Visher, J. S., \& Pasley, K. (2003). Remarriage Families and Step-Parenting. Normal Family Processes: Growing Diversity and Complexity, 3, 153-175. 
Submit or recommend next manuscript to SCIRP and we will provide best service for you:

Accepting pre-submission inquiries through Email, Facebook, LinkedIn, Twitter, etc. A wide selection of journals (inclusive of 9 subjects, more than 200 journals)

Providing 24-hour high-quality service

User-friendly online submission system

Fair and swift peer-review system

Efficient typesetting and proofreading procedure

Display of the result of downloads and visits, as well as the number of cited articles Maximum dissemination of your research work

Submit your manuscript at: http://papersubmission.scirp.org/

Or contact aasoci@scirp.org 